\title{
ENTRE CANHÕES E TEMPESTADES: METÁFORAS NA LINGUAGEM POLÍTICA DA IMPRENSA DO SÉCULO XIX
}

\section{Álvaro Antonio Klafke ${ }^{1}$}

\author{
Murillo Dias Winter ${ }^{2}$
}

\begin{abstract}
Resumo: O trabalho investiga os usos das metáforas na linguagem política da imprensa no início do século XIX. Em um período em que os jornais eram utilizados como um dos principais instrumentos da atividade política, diferentes formas de convencimento eram mobilizadas nos impressos com o objetivo de formação da opinião pública. Entre as mais recorrentes estavam as metáforas, ainda pouco estudadas. Para tanto, nos concentramos em dois momentos específicos e dois tipos de metáforas recorrentes. Em primeiro lugar, as metáforas bélicas, sobre a guerra, durante os anos da Revolução Farroupilha (1835-1845). Durante os conflitos no Rio Grande do Sul a imprensa legalista, aliada ao Império do Brasil, usava das construções retóricas sobre o conflito para atacar os farroupilhas e reafirmar seu projeto de unidade. Já a natureza e a geografia eram utilizadas como metáforas nos jornais contra o Brasil durante os anos de existência da província Cisplatina (1821-1828). As paisagens e o clima típico da região serviram como ferramenta de construção de diferenças entre os locais e o invasor. Ambos os casos demonstram a operacionalidade das metáforas e a importância de seu estudo para a compreensão da linguagem, em transformação no Oitocentos.
\end{abstract}

Palavras-chave: Imprensa. Linguagem política. Metáforas.

\section{INTRODUÇÃO}

Existe um reconhecimento tácito e generalizado, entre os historiadores e pesquisadores de outras áreas - sobretudo quando lidam com textos, em diferentes formas e suportes - que as figuras de linguagem exercem papel fundamental na comunicação. Entretanto, é menos comum a atividade de reflexão sobre a forma como elas se constituem e que efeitos exercem no discurso. Aqui, tratamos

1 Doutor em História pela Universidade Federal do Rio Grande do Sul (UFRGS). Analista pesquisador na Fundação de Economia e Estatística do Rio Grande do Sul (FEE). Contato: klafkealvaro@gmail.com. 2 Doutor em História Social pela Universidade Federal do Rio de Janeiro (UFRJ). Contato: murillodiaswinter@hotmail.com 
especificamente de recursos metafóricos, então, como elemento para analisar alguns exemplos da imprensa na região platina e no Rio Grande do Sul na primeira metade do século XIX. O objetivo, modesto, não é o de um estudo sobre o tema, objeto de imemorial reflexão da filosofia e campos afins. Trata-se de elencar algumas ideias básicas, de alguns poucos autores, que, esperamos, cumpram a dupla função de, por um lado, propor indicações de leitura, e, de outra parte, nos permita embasar a forma como analisamos as fontes, os jornais, em relação ao uso recorrente de imagens metafóricas.

As linhas que seguem buscam apresentar breves considerações de caráter teórico sobre a metáfora Ponderar acerca dos seus instrumentos de análise passou a ser tarefa inescapável do pesquisador. Nessa direção, seguimos Javier Sebastián, para quem

\begin{abstract}
El análisis de una conceptualidad y de una metaforicidad extraña hace que el propio historiador se historice, esto es que tome conciencia del carácter contingente y problemático de sus instrumentos de análisis. En efecto, estamos convencidos de que una de las tareas inaplazables de la historiografía es reflexionar sobre los marcos epistemológicos - incluyendo las grandes categorías clasificatorias - que han venido ordenando las tareas del historiador, el sociólogo o el politólogo (Sebastián, p. 26).
\end{abstract}

Analisar, portanto, a "metaforicidade" de um determinado período, sem desconsiderar, claro, o veículo e o público a quem ela se destina, obriga à historicização do próprio ofício. Para além de tentar apreender sentidos intrínsecos aos textos, relativos ao seu contexto, o que o alerta do autor, nos parece, também indica, é a contingência e mesmo a provisoriedade de nossa forma de ler o passado, uma vez que a ancoramos em pressupostos teóricos cujos marcos epistemológicos não são fixos. Para ser mais direto: as reflexões sobre a metáfora, seu desenvolvimento ao longo do tempo, e o acesso, necessariamente parcial e arbitrário que temos a elas, também condicionam nosso olhar e nossa interpretação acerca de seu uso no passado - esse passado em constante modificação.

Nesse sentido, Eduardo de Bustos elencou um conjunto de concepções tradicionais sobre metáfora e de alternativas teóricas para a sua interpretação, referentes aos campos da linguística, da literatura e da filosofia (Bustos, 2000, p. 1322). Na obra do autor, temos uma visão panorâmica - e, em consequência, não exaustiva - da contingência referida, sobretudo a partir de uma análise sintética, em amplo recorrido histórico, das formas como a metáfora foi considerada, prin- 
cipalmente à luz da filosofia e da teoria da linguagem (Bustos, 2000, p. 34-61).

Importa destacar, para a nossa leitura, um aspecto que, por vezes, passa despercebido na análise: o fato de que o uso das metáforas extrapola seus efeitos meramente instrumentais, de convencimento. E, além disso, de que não se trata, quando as expressamos, de uma operação puramente racional, de um ato de vontade intelectualmente fundamentado. Em certo sentido, isso já foi salientado por diversos autores, sobretudo aqueles da chamada "teoria cognitiva". Ulrike Schröder resume a novidade dessa visão teórica:

Concomitantemente com o surgimento da linguística cognitiva, a exclusiva reflexão impressionista de metáforas foi superada, quer dizer, metáforas não são percebidas mais de forma isolada como um fenômeno exclusivo de língua, mas sim, como uma expressão de estruturas conceituais e de capacidades cognitivas. Portanto, os fundadores da teoria cognitiva das metáforas, Lakoff e Johnson, compreendem metáforas como a reflexão de uma estrutura de pensamento básica dentro da linguagem, que nos permite entender um domínio conceitual não estruturado por recorrer a um outro domínio de experiência conhecido (Schröder, 2004, p. 243-144).

Os autores que aceitam essa tese, então, as percebem - as metáforas -, "em nosso comportamento de linguagem cotidiano, recusando, desta forma, uma visão exclusivamente retórica da metáfora" (SCHRÖDER, 2004, p. 251).

Emmánuel Lizcano, em direção semelhante, sublinha a centralidade da metáfora na estruturação das emoções e pensamentos, desde o plano mais cotidiano até o mais técnico ou político (Lizcano , 2006, p. 27). O autor, ademais, chama a atenção para o caráter relativamente coercitivo do uso das metáforas: "Creemos estar expresándonos libremente y estamos diciendo lo que la estructura de nuestra lengua y la multitud de metáforas que la habitan (que nos habitan) nos obligan a decir" (Lizcano ,2006, p. 27). Tal formulação assume relevância contra o risco de cair no reducionismo de pensar que a utilização retórica das metáforas, ou qualquer outra figura de linguagem, seria resultado de uma elucubração mental absolutamente controlada, com vistas a provocar determinados efeitos nos ouvintes ou leitores.

Em reforço a essa abordagem, González García sustenta que o papel desempenhado pela metáfora é maior do que o de mero adorno estilístico que poderia ser substituído por um enunciado não metafórico (García, 2006, p.14). O autor postula, seguindo Mark Johnson, que não se trata de uma simples figura retórica, mas "una estructura penetrante e indispensable de la comprensión humana, 
mediante la cual captamos figurada e imaginativamente el mundo. Dicho brevemente, no sólo hablamos en metáforas, sino que además pensamos y conceptualizamos la realidad social en metáforas" (García, 2006, p.14).

O que os aportes da teoria cognitiva e conceitual da metáfora propiciam, então, é um olhar sobre os escritos políticos da imprensa oitocentista que vai buscar, mais do que perceber a forma como os redatores se utilizavam da retórica para a pregação, um acercamento de uma visão de mundo específica. Visão que era compartilhada com seus potenciais leitores, e no qual as metáforas, onipresentes, eram produto de uma maneira particular de pensar e conceitualizar a sociedade, estruturas através das quais era percebida, "figurada e imaginativamente", como bem expressa García, o mundo circundante e articulados os projetos de organização social dos Estados em disputada formação.

Ao analisar os textos da época, evidencia-se que a projeção de futuro, condicionada ao resultado das lutas do presente, impunha a ideia do próprio tempo como lugar, o que já é uma metáfora poderosa, e da qual ainda hoje compartilhamos. "El futuro al que ahora nos percibimos atados no deja de ser un lugar, tan lugar como antes era el pasado" (Lizcano, 2006, p. 69). Essa noção, tão verdadeira e assimilada atualmente, entretanto, tem uma gênese. E sua construção, precisamente, está vinculada a esse período de fundação das bases de uma nova sociedade, socialmente ancorada na ordem burguesa e politicamente legitimada pelo poder do Estado nacional. Trata-se apenas de um exemplo, entre outros, da forma como poderia ser - e era - tematizado metaforicamente a percepção de um elemento crucial do discurso político de então, o tempo, sobretudo quando se tratava, invariavelmente, de "abandonar" o passado e "caminhar" na direção de um futuro de progresso.

Mudanças e transformações, ideia de progresso que ofereceram poderosas imagens e um arcabouço de sentidos e metáforas ao longo das profundas mudanças políticas e sociais das últimas décadas do Século XVIII e primeiras do XIX, como salienta Fernández Sebastián:

Viejas y nuevas metáforas como el imperioso torrente de la opinión, la irresistible luz de la razón, el edificio o la nave del Estado, el cuerpo de la nación, el equilibrio de los poderes, y muchas otras llenaron el lenguaje político en esas décadas decisivas de un repertorio de poderosas imágenes -varias de ellas presentes en casi todas las lenguas de Europa occidental- que aparecen entretejidas con los incipientes conceptos de nación, libertad, independencia, soberanía, constitución, liberalismo, opinión pública, representación o clase media (Fernández Sebastián, 2009, p. 11). 
Semelhantes a esse, o periodismo de então estava repleto de imagens metafóricas que, simultaneamente, demonstravam um estado de coisas, reforçavam alguns aspectos da forma de considerar a sociedade e propunham soluções e caminhos alternativos, como observaremos.

\section{2. "LÁ VAI BALA": METÁFORAS BÉLICAS}

As primeiras décadas do século XIX conformaram um período crucial para a definição dos novos estados nacionais - sobretudo nas Américas - e para a reformulação dos já existentes, adequando-os à agenda liberal burguesa então em voga. Os conflitos militares eram acompanhados por intensos debates políticos travados na imprensa. Tratava-se de uma época que o historiador português Oliveira Martins caracterizou, com eloquência e acerto, como "da palavra e do tiro" (Apud VIEIRA, 2005, p. 76). Tal caracterização, embora referida ao contexto lusitano, abrange, também, a realidade sul-americana. A precisão da fórmula criada pelo autor nos serve para direcionar o olhar a um tipo específico de metáforas, bastante utilizadas então: as de referências bélicas.

A ideia de que se estava travando um "combate" de posições políticas, cujas armas eram a pena, o papel e as prensas rudimentares, era comum aos diversos redatores. Daí a abundância de exemplos da "guerra" nos escritos do período. Os próprios títulos de alguns periódicos apontavam para isso: O Artilheiro, em Porto Alegre, e seu homônimo do Porto, em Portugal; Sentinela da Liberdade, também de Porto Alegre. No vizinho Uruguai, igualmente envolvido em conflitos de facções, surgiram folhas como El Lancero em Campaña, El Artillero de la Línea ou Estrella o Cañón de la Libertad.

Em Porto Alegre, o caso mais emblemático foi o do Artilheiro. O semanário da capital da então província de São Pedro do Rio Grande do Sul circulou, presumivelmente, entre julho de 1837 e julho de 1838. Não se tem confirmação segura de quem o redigia, apenas a informação de que era impresso na tipografia de Claude Dubreuil. A despeito de que metáforas de cunho militar eram usuais, a abundância de sua ocorrência no periódico tinha uma explicação imediata. Viviam-se os primeiros anos da guerra civil - movimento posteriormente consagrado como Revolução Farroupilha -, e a cidade estava submetida ao cerco das tropas rebeldes. Nesse contexto, o jornal manteve-se, firme e constantemente, na defesa de um modelo de Império monárquico centralizado, em feroz oposição aos farrapos. 
A "guerra" travada pelo Artilheiro manifestava-se na linguagem violenta, sarcástica e, sobretudo, metaforicamente permeada de imagens bélicas. Os títulos das seções e de alguns textos eram eloquentes: "Lá vai bala rasa"; "Metralhada”; "Lá vai bomba"; "Estocada”; "Lá vai granada”; "Cutilada”; "Tiro de metralha”; "Bala ardente". Tais exemplos correspondiam, conotativamente, às atividades próprias do redator - ou dos redatores - que se apresentava como artilheiro. Assim, independentemente do teor da sua argumentação, a própria linguagem transmitia a sensação de confronto violento. De fato, embora não possamos aferir o quanto a terminologia utilizada correspondia à situação vivenciada na cidade, a situação era conflitiva. Isso transparecia desde o início da publicação, quando era dado o aviso: "Nada de susto, Camaradas! Suas mercês há perto de 3 meses acostumados a ouvir roncar o bronze, e agora espantarem-se do Artilheiro?" (n.1, 22/jul/1837).

Com aquele público acostumado a "ouvir roncar o bronze" dos canhões, portanto, havia uma familiaridade que fazia com que o repertório retórico fosse perfeitamente entendido. Em toda a sua atividade de crítica política, as metáforas de cunho militar sustentavam uma argumentação agressiva. É o caso de uma admoestação, que soa também como ameaça, direcionada ao presidente da província, Feliciano Nunes Pires, na seção "Lá vai bala rasa".

O Artilheiro quer que impere a Lei em todo o caso, e mais desejava, quando falasse dos atos de S. Ex., dar salvas de alegria, do que gastar balas, bombas, etc. siga S. Ex. a risca a Lei, não procure senão fazer triunfar a Causa da Nação, e emende alguns erros, que o Artilheiro será o seu maior Apologista, e assim terá o Sr. Nunes conceito, popularidade, e força moral, como lhe convém, d’outro modo não só realizará o que os Periódicos da Corte dizem dele, como terá o Artilheiro sempre pela proa, com sua Peça, e Obus (n. 3, 5/8/1837).

$\mathrm{O}$ ataque, e a ameaça, eram devido à política de entendimento que o redator atribuía ao presidente em relação aos rebeldes. Importa destacar, entretanto, a forma como o texto estava estruturado, totalmente saturado de imagens que remetiam ao conflito aberto.

O estilo agressivo se mantinha mesmo quando a intenção era fazer um apelo à civilidade. Para protestar contra alguns "periodiqueiros", segundo sua própria expressão, que não remetiam suas folhas, como era praxe, ele desferia uma "Cutilada", citando o redator da Gazeta Mercantil, de quem 
conheceu a sua grosseria. O finado Correio, apesar das balas do Artilheiro, nunca faltou à civilidade, o Sete d'Abril, o Cincinnato, e outros papéis interessantíssimos da Corte, com os quais se não pode equiparar a Gazeta Mercantil, [...], não têm faltado, retribuindo com as suas folhas (n. 16, 14/11/1837. Grifos nossos.).

Quando o periodista frisa que não houve reprimendas de outras folhas, "apesar das balas", há a admissão de que, a despeito de estarem, eventualmente, em campos distintos, sua artilharia é retórica, e existe um grau de entendimento recíproco do tipo de combate que se travava pela imprensa. A referência ao Correio da Liberdade, jornal igualmente legalista, é entendida considerando a circunstância de que o texto do Artilheiro, além de dar combate aos farrapos, voltava-se também contra os moderados, os defensores de uma possível "terceira via", grupo no qual o Correio poderia ser alinhado.

A opção "centrista", digamos assim, entre os extremos do republicanismo e da monarquia absoluta, estava presente na imprensa do período. Tal modelo de pensamento e ação política era criticado pelo Artilheiro em virtude de sua afiliação ao monarquismo centralizada e forte, sem consideração por contrapesos parlamentares, por exemplo. Mas é sintomático que mesmo os moderados, como o Correio da Liberdade, também se utilizassem de metáforas bélicas. Esse periódico declarava

uma crua e desapiedada guerra aos Anarquistas, aos recolonizadores, aos Democratas, e finalmente a todos os que de qualquer modo que seja, intentem transformar a forma de Governo por nós tão felizmente adotada e jurada (n. 17/4/1831. Grifos nossos).

Ou seja, a noção de conflito, cuja imagem mais imediata e entendível era a de "guerra", com ou sem adjetivos, era generalizada no período. Perceba-se que este último jornal era anterior ao Artilheiro, anterior à guerra civil e ao cerco da cidade. Contudo, ele saíra numa conjuntura também bastante combativa, em termos políticos. Tratava-se do período imediatamente posterior à abdicação de Pedro I, quando ainda estava em aberto, e sendo muito disputado, o desfecho do processo.

O compartilhamento linguístico e de ideias perpassava todo o espectro político, fazendo com que distintos grupos, em diferentes posições, utilizassem uma linguagem semelhante. O Recopilador Liberal, jornal porto-alegrense de 1833, simpático à causa farroupilha que já se desenhava, queixava-se assim dos agentes 
do conservadorismo monárquico que agiam nas sombras, segundo sua visão: "Homens vis, abjetos e covardes, por que vos não atrevei apresentar-vos na arena como gladiadores, por que não vos animais a acometer-nos cara a cara? Por que nos fazeis essa guerra de tigre, e de emboscada?" (Recopilador Liberal, n. 134, 6/11/1833. Grifos nossos.)

No excerto temos uma ampliação da recorrente metáfora da guerra. A acusação era de que se travava uma guerra covarde, de artifícios dissimuladores. Honroso seria enfrentar o combate político de peito aberto, frente a frente. Para reforçar essa imagem, são introduzidas as figuras do gladiador e da arena, ator e palco de uma disputa mais digna, por que mais corajosa. A imagem da guerra, neste caso, é ligeiramente modificada, em relação ao seu sentido mais usual. Tais nuances permitem refletir, com Javier Sebastián, que, "lejos de constituir un repertorio universal e intemporal, la mayoría de las metáforas se usan en un determinado marco cultural, espacial y cronológico, y una misma metáfora de base puede sufrir cambios importantes, en función de diversas circunstancias" (p. 18). As circunstâncias que contribuem para alterar o uso da figura de linguagem, pelo redator do Recopilador, residem no fato de que, quando da sua publicação, o contexto político, embora tensionado, ainda era de articulações mais ou menos secretas. Não se chegara, todavia, ao conflito armado, situação que levou a um uso muito mais intenso da linguagem baseada em termos militares.

O que os exemplos demonstram, em seu conjunto, é a recorrência das metáforas bélicas. Por um lado, é evidente que o seu uso abundante estava relacionado à situações conjunturais diretamente perceptíveis, ou seja, ao próprio cotidiano vivenciado pelos redatores. Por outro lado, seria simplista limitar a análise a tal automatismo. Imagens e termos evocativos da guerra fazem parte, há muito, de nossa forma de expressão. Trava-se guerra contra a pobreza, combate-se o câncer, mobilizam-se todas as armas na batalha pelo voto. Importa destacar, contudo, que no período em questão, o repertório metafórico estava fortemente engajado ao processo de construção do Estado e da Nação. Então, para além da conjuntura que, eventualmente, era de efetivo conflito, somava-se a função unificadora do mito guerreiro, a cimentar as precárias bases políticas e sociais dos países em disputada construção. 


\section{COMO A TEMPESTADE: METÁFORAS DA NATUREZA}

O processo de independência do Brasil tem como uma das suas características e efeitos imediatos mais notórios a explosão da atividade de imprensa, marcando o ponto mais alto de um crescimento que ocorria desde da mudança da família Real lusitana para terras americanas (Morel). Durante a década de 1820 diferentes províncias, do Maranhão a Cisplatina, passaram a contar com jornais e panfletos produzidos nestes espaços. Mais além da discussão sobre os eventos internacionais e a conjuntura política conturbada do período, as demandas locais e regionais eram articuladas a este contexto, tornando-se parte fundamental do jogo político em diferentes escalas. Distintas estratégias retóricas eram mobilizadas para sobressair seus projetos diante dos rivais na arena política. A natureza e a geografia específica desses locais em contraste com as diferenças propiciadas pelas dimensões do Império em construção foram uma ferramenta metafórica explorada.

Na província Cisplatina, entre os anos de 1822 e 1823, a presença brasileira era cada vez mais contestada. Afinal, os vínculos políticos da região haviam sido com Portugal e na mudança de conjuntura a população deveria ser consultada e a sua soberania respeitada, quando o que aconteceu foi a manutenção do poder pelo Brasil. Umas das principais maneiras de divulgar esses movimentos e marcar a posição contrária de grande parte da população cisplatina era através da imprensa. Nesse sentido, três jornais foram significativos nesse processo: $L a$ Aurora, o El Pampero e o El Aguacero. Nas suas páginas a geografía específica do Prata foi movilizada constantemente em busca de liberdade e independência frente ao governo liderado pro D. Pedro.

O La Aurora foi o primeiro a surgir. Publicado semanalmente, até a edição de número quatorze aos sábados e posteriormente todas as quartas-feiras, pela Imprenta de Torres, o periódico teve dezessete edições em numeração contínua, vendidas por um real. O prospecto da publicação foi distribuído no dia 14 de dezembro de 1822 e destacava os seus objetivos de iluminar a região e lutar pela liberdade:

Es un fuego que virtualmente alimentavan en el seno mismo de la opresion dispuesto a inflamarse con el menor soplo que lo agitarse. Que este fuego se concentre en un solo cuerpo que presida á sus destinos es el objeto de sus anhelos. Este astro luminoso aparecerá sin duda, orientales. 
La aurora le precede y el sol se levantará sobre un horizonte que nunca mas vuelva á obscurecerse. (n. 1, 14/12/1822)

A metáfora da aurora, do amanhecer, relacionada à independência é uma das mais frequentes no mundo ibero-americano. Porém, tem uma tradição que remonta a períodos anteriores. Como destaca Javier Fernández Sebastián, as alegorias solares e de iluminação são comuns na tradição cristão e na Monarquia Católica, característica do mundo ibérico, também foram comuns, como pode se supor, durante o período do iluminismo, ainda que recebido de maneira circunspecta em Portugal e na Espanha. O discurso da razão, a luz da aurora brilhante da filosofia e das ciências eram abundantes durante o século XVIII. Ainda que para elite conservadora e os governantes que não gostariam de ter o mesmo fim de Luís XVI, nas revoluções do final do século, o imaginário da luz, da aurora e da iluminação foi acrescentado e politizado, refiara-se também ao advento de uma nova era que poria fim no despotismo, na ignorância e na opressão. Raiava no horizonte, a aurora de novos tempos (FERNÁNDEZ SEBASTÍAN, 2012, p. 21).

Nas primeiras décadas do Oitocentos, existiam, por exemplo, periódicos que tinham em seu título Aurora, sendo a Peruana, a Fluminense e a do Chile, todos publicanos dentro do contexto das independências. A sua principal utilização é para a demonstração do nascimento de uma nova era, um recomeço para determinado país ou região. O passado geralmente é associado a um período sombrio, de escuridão que, a partir da ação e do trabalho no presente, poderia ser modificado e, no futuro, substituído por um período de avanço, iluminação e liberdade. A partir do ano de 1808, em Portugal e Espanha, na luta contra a invasão napoleônica, diversos periódicos e panfletos condenavam a presença francesas e defendiam a liberdade, o renascimento político e social de seus países através dessa metáfora. Nesse sentido, por exemplo, a constituição de Cádiz era um sol que iluminaria os tempos nebulosos do absolutismo, o passado monárquico também Associação que permaneceu na América ibérica na luta de independência ao logo de toda a década posterior. Neste contexto, eram Portugal e Espanha, antigas metrópoles que eclipsavam a liberdade e o desenvolvimento das colônias americanas em luta por sua independência.

No dia 19 de dezembro de 1822 é publicado, pela Imprenta de Torrez, o periódico El Pampero. Vendidas a um real e meio, as quatorze edições do jornal, incluindo a extraordinária Ráfaga del Pampero, circularam todas as quartas-feiras entre dezembro de 1822 e maio de 1823. Dividindo suas páginas entre 
notícias locais, textos analíticos e políticos e reproduções de jornais europeus e buenairenses. Na primeira edição, os redatores utilizam a analogia entre o vento e o nome do periódico para definir as vinculações políticas e os objetivos da publicação:

EL PAMPERO es el viento favorito del Rio de la Plata: tras un tiempo turbulento y pesado él nos trae la serenidad y la bonanza. A su aspecto huyen aterrados los vientos calientes del norte que abrasan nuestras mieses, que esterilizan nuestros campos, que aniquilan nuestras haciendas; y si alguna vez osados se atreven á disputarle el puesto, sañudo y terrible como la ira de Júpiter, los arrastra en su furia hasta el Trópico, y van á ocultarse en sus montañas. virtudes del pampero? ¿Hay alguno que no le dese? Creemos que no. En estos últimos días particularmente en que la lluvia, la cerrazón, y pesadez han sido tan constantes como poco comunes, todos han manifestado su ansiedad por un pampero, $\mathrm{y}$ no se oía decir sino, ya aclarada, ya tenemos pampero (n.1, 19/12/1822).

Os redatores transferiram características da geografia local, do clima platino, para a moral e os hábitos dos orientais. A população deveria ser forte e obstinada para varrer, assim como os fortes ventos fazem, os invasores da região. É significativo notar que a metáfora do vento é relacionada ao movimento, eles alteram a situação e transformam a paisagem do local em que passam. Neste sentido, os ventos vindos do norte, mesmo local do Brasil, acabaram com as plantações, devastaram as fazendas e provocaram a ira dos habitantes locais. Efeitos que destacam as principais reclamações do governo de Carlos Frederico Lecor, desde que a posse da região havia se transferido de Portugal para o Brasil, o chefe militar era acusado de permitir grandes transferências de cabeça de gado dos campos cisplatinos para as propriedades dos rio-grandenses, também a guerra provocada havia destruído toda a base produtiva local, as fazendas, base da economia desde o período colonial (Alonso, 1972, p. 31).

Em contraponto aos ventos vindos do norte, estava o pampeiro, característico da região. Mais uma vez é enfatizada a ideia de movimento, entretanto, este é positivo. Depois de um período turbulento e pesado, o pampeiro é responsável por trazer a bonança e a serenidade. Desse modo, o movimento, vindo do norte, que acabou com a liberdade da região, poderia ser ultrapassado por um mais forte, natural da região, e que traria de volta o desenvolvimento.

No mês de abril de 1823, é publicado o prospecto de um novo periódico, o El Aguacero. Sem data fixa para serem impressas e vendidas, as oito edições circularam entre abril e outubro de 1823 , inicialmente sob a responsabilidade 
da Imprenta de Torres o último número, no entanto, foi impresso e vendido sob a responsabilidade da Imprenta de los Ayllones y Compañia. O jornal difere das publicações anteriores, justamente, por utilizar-se de muito humor para atacar frontalmente as publicações periódicas cisplatinas e os antagonistas de seu projeto independente e republicano para a região. Para os redatores, esse recurso é utilizado para chamar a atenção dos leitores e facilitar a compreensão de discursos políticos considerados mais rígidos: "hacer insensiblemente provechosas las doctrinas y discursos áridos, fríos y secos” (n.3, 08/05/1823). Ou seja, a metáfora da água, a chuva do Aguacero serviria em primeiro plano para umidificar os discursos, torna-los mais palatáveis, mais vivos e, assim, mais próximos de seu público leitor.

Para então, divulgar o objetivo e o sentido mais amplo da metáfora, demonstrar que a natureza colocará a situação política em seu lugar:

\begin{abstract}
No es nuevo que los Aguaceros sean acompañados de truenos, relámpagos, rayos y alguna vez fenómenos que la próvida naturaleza encierra en su hondo seno: pero la lluvia benéfica humedecerá la agostada tierra, y la preparará á producir sazonados frutos, mientras que el filósofo ni se asustara del estrépito de la tormenta, ni será alcanzado por los rayos que observe desde su defendido gabinete: la electricidad de las luces que le cercan contendrá su fuego abrasador. Tal es nuestro destino. (n.3, $08 / 05 / 1823$ )
\end{abstract}

Para os redatores as ligações entre Império do Brasil e a Cisplatina não eram naturais e, portanto, mesmo que houvessem períodos difíceis o caminho era a separação. Ruptura que seria acelerada com a luta pela liberdade e pela ativa participação política. Elementos fundamentais para a publicação. Por fim, em um período de superação do período colonial e construção de novos corpos políticos e novas identidades ligadas a estes projetos de tipo nacional a operacionalidade das metáforas da natureza permitiu construir um apelo jutno da população para demonstrar novos pertencimentos e, sobretudo diferenciar-se daqueles que não faziam aos projetos políticos em voga pela imprensa.

\title{
4. CONSIDERAÇÕES FINAIS
}

As metáforas, significativas por si só, surgiam entremeadas e em apoio de novos conceitos do ideário político, ou de velhos conceitos com acepções distintas. Junto a estes, portanto, refletiam e desenhavam um novo tipo de "edifício" 
político e social. Nesta "construção", que também pressupunha algum nível de destruição do antigo, a linguagem metafórica valeu-se bastante das imagens relacionadas à guerra e à natureza. Portanto, em uma época conflitiva e de disputas bélicas as metáforas eram um meio eficiente de reelaborar e dar sentido a essa realidade. Fruto de um contexto em transformação, foram fundamentais para dar sentido e explicar elementos fundamentais das lutas em voga. A natureza construiu um pano de fundo, um espaço para ser associado ao tempo e a mudança, ligando tempo e espaço. Construiu uma paisagem para que uma nova linguagem em construção pudesse ser compreendida na mesma medida que era parte ativa das mudanças nessa "paisagem" social e política.

Assim, prestar atenção e se dedicar à dimensão metafórica da linguagem é uma porta de acesso a um universo de sentidos amplos e complexos em que atores sociais buscam dar sentido a mudanças políticas, sociais e simbólicas profundas. Ainda que estes elementos não se reduzam a linguagem, é através dela que eles são mediados com o mundo. Quanto mais ferramentas o historiador tiver disponíveis para acessar esse universo de sentidos, maior são as oportunidades para compreender a complexidade do mundo que os cerca.

\section{REFERÊNCIAS}

ALONSO, Rosa et al. La oligarquía Oriental en la Cisplatina. Montevidéu: Pueblos Unidos, 1970.

BUSTOS, Eduardo de. La metáfora: ensayos transdisciplinares. Madri: Fondo de Cultura Económica, 2000.

GARCÍA, José M. González. La diosa Fortuna: metamorfosis de una metáfora política. Madri: Machado Libros, 2006.

KLAFKE, Álvaro Antonio. Antecipar essa idade de paz, esse império do bem. Imprensa periódica e discurso de construção do Estado unificado (São Pedro do Rio Grande do Sul, 1831-1845). Porto Alegre: EDIPUCRS, 2014.

LIZCANO, Emmánuel. Metáforas que nos piensan. Sobre ciencia, democracia y otras poderosas ficciones. Madri: Ediciones Bajo Cero/Traficantes de Sueños, 2006.

ROMANO, María Laura. O Artilheiro (1837-1838). Un periódico de trincheira. Varia Historia, Belo Horizonte, vol. 34, n. 66, p. 791-815, set/dez 2018. 
SCHRÖDER, Ulrike. Os precursores filosóficos da teoria cognitiva das metáforas. Cadernos de Estudos Linguísticos 46(2), Campinas - Jul./Dez. 2004, p. 243-252.

FERNÁNDEZ SEBASTIÁN, Javier. "La crisis de 1808 y el advenimiento de un nuevo lenguaje político. ¿Una revolución conceptual?”, in: Alfredo Ávila y Pedro Pérez Herrero (eds.), Las experiencias de 1808 en Iberoamérica. México: UNAM/Universidad de Alcalá, 2008.

FERNÁNDEZ SEBASTÍAN, Javier. “Conceptos y metáforas en la política moderna. Algunas propuestas para una nueva historia político-intelectual”. In Jordi Canal y Javier Moreno Luzón (eds.). Historia cultural de la política contemporánea. Madrid, Centro de Estudios Políticos y Constitucionales, 2009.

FERNÁNDEZ SEBASTÍAN, Javier. La aurora de la libertad. Los primeros liberalismos en el mundo iberoamericano. Madrid: Marcial Pons, 2012.

VIEIRA, Benedicta Maria Duque. A formação da sociedade liberal (1815-1851). Lisboa: CEHCP-ISCTE, 2005. 


\title{
ENTRE CAÑONES Y TORMENTAS: METÁFORAS EN EL LENGUAJE POLÍTICO DE LA PRENSA DEL SIGLO XIX
}

\begin{abstract}
Resumen: Este artículo investiga los usos de las metáforas en el lenguaje político de la prensa a principios del siglo XIX. En un momento en que los periódicos se usaban como uno de los principales instrumentos de la actividad política, se movilizaron diferentes formas de persuasión impresas con el propósito de formar la opinión pública. Entre las más recurrentes estaban las metáforas, todavía poco estudiadas. Para hacerlo, nos centramos en dos momentos específicos y dos tipos de metáforas recurrentes. En primer lugar, metáforas bélicas sobre la guerra durante los años de la Revolución Farroupilha (1835-1845). Durante los conflictos en Rio Grande do Sul, la prensa legalista, aliada con el Imperio de Brasil, utilizó las construcciones retóricas sobre el conflicto para atacar a las farroupilhas y reafirmar su proyecto de unidad. La naturaleza y la geografía se utilizaron como metáforas en los periódicos contra Brasil durante los años de existencia de la provincia Cisplatina (1821-1828). Los paisajes y el clima típicos de la región sirvieron como herramienta para construir diferencias entre los sitios y el invasor. Ambos casos demuestran la operatividad de las metáforas y la importancia de su estudio para comprender el cambio de lenguaje en los Ochocientos.
\end{abstract}

Palabras clave: Prensa. Lenguaje político. Metáforas.

\section{BETWEEN CANNONS AND STORMS: METAPHORS IN THE 19TH CENTURY PRESS POLITICAL LANGUAGE}

\begin{abstract}
This paper investigates the uses of metaphors in the political language of the press in the early nineteenth century. At a time when newspapers were used as one of the main instruments of political activity, different forms of persuasion were mobilized in print for the purpose of forming public opinion. Among the most recurring were metaphors, still poorly studied. To do so, we focus on two specific moments and two types of recurring metaphors. Firstly, warlike metaphors about war during the years of the Farroupilha Revolution (1835-1845). During the conflicts in Rio Grande do Sul the legalistic press, allied with the Empire of Brazil, used the rhetorical constructions about the conflict to attack the farroupilhas and reaffirm their unity project. Nature and geography were used as metaphors in newspapers against Brazil during the Cisplatina province's years of existence (1821-1828). The landscapes and climate typical of the region served as a tool to build differences between the sites and the invader. Both cases demonstrate the operability of metaphors and the importance of their study for understanding the changing language in the Eight Hundreds.
\end{abstract}

Keywords: Press. Political language. Metaphors. 